\title{
A revisão das antinomias na psicologia: Do racionalismo cientificista ao estruturalismo
}

\author{
The review of antinomies in psychology: From scientific rationalism to structuralism
}

Danilo Saretta Verissimo

Doutor em Psicologia pela Universidade de São Paulo (USP), doutor em Filosofia pela Université Jean Moulin - Lyon 3, professor assistente doutor do Departamento de Psicologia Evolutiva, Social e Escolar da Faculdade de Ciências e Letras de Assis, Universidade Estadual Paulista (Unesp), Assis, SP Brasil, e-mail:

danilo.verissimo@gmail.com

Recebido: 29/08/2011 Received: 08/29/2011

Aprovado: $11 / 10 / 2012$ Approved: 10/11/2012

\begin{abstract}
Resumo
Neste ensaio, sustentamos a ideia de que o pensamento estruturalista faz parte da crítica espontânea aos reducionismos que cercam a psicologia. Partimos da cisão radical entre o ponto de vista cientificista e o da metafísica que se expressa nos projetos de psicologia científica do fim do século XIX. Em seguida, destacamos a importância da perspectiva estruturalista na revisão das relações antinômicas do subjetivo e do objetivo operada no seio da Psicologia ao longo do século XX. Mostramos que a rejeição da causalidade unilinear em prol da causalidade em rede freou o avanço das teorias unilaterais, ou reducionistas, na psicologia. Consideramos, ademais, a ideia de estrutura como ponto de convergência entre a psicologia e a filosofia. Acima de seu caráter explicativo, a noção de estrutura revela um registro epistemológico capaz de reaproximar a psicologia da relativização do ideal de neutralidade cientificista. A importância do pensamento estruturalista na psicologia conduz-nos à consideração da história do conhecimento psicológico enquanto tipo de investigação pertencente à história da cultura.
\end{abstract}

Palavras-chave: Estruturalismo. Cientificismo. Psicologia filosófica.

\begin{abstract}
In this essay, we sustain the idea that structuralist thinking is part of spontaneous criticism against the reductionisms that surround psychology. We depart from the radical split-up between the scientific viewpoint and that of metaphysics, expressed in the end-19th century scientific psychology projects. Next, we highlight the importance of the structuralist perspective in the review of the antinomic relations between the subjective and objective, operated at the heart of psychology throughout the 20th century. We show that the rejection of unilineal causality in favor of network causality curbed the advancement of unilateral or reductionist theories in psychology. Moreover, we consider the idea of structure as a point of convergence between psychology and philosophy. More than its explanatory nature, the notion of structure reveals an epistemological register capable of re-approximating psychology to the relativization of the ideal of scientific neutrality. The importance of structuralist thinking in psychology makes us consider the history of psychological knowledge as a type of research that belongs to cultural history.
\end{abstract}

Keywords: Structuralism. Scientificism. Philosophical psychology.

Psicol. Argum. 2013 jul./set., 31 (74), 537-546 
Neste ensaio de caráter panorâmico, partimos da cisão radical entre o ponto de vista cientificista e o da metafísica que se expressa nos projetos de psicologia científica do fim do século XIX. Em seguida, destacamos a importância da perspectiva estruturalista na revisão das relações antinômicas do subjetivo e do objetivo operada no seio da psicologia ao longo do século XX. Contamos mostrar que o pensamento estruturalista faz parte da crítica espontânea aos reducionismos que cercam a psicologia. A ideia de estrutura, ou de forma, é tratada como ponto de convergência entre a psicologia e a filosofia. Mais do que um modelo explicativo, a noção de estrutura possui um registro epistemológico capaz de reaproximar a Psicologia do processo, próprio às humanidades, de relativização do ideal de neutralidade cientificista ${ }^{1}$.

\section{Filosofia e ciência}

Segundo Merleau-Ponty (2000, p. 34), os sistemas filosóficos clássicos constituem tentativas da imaginação filosófica para se dar representações manejáveis da verdade. Algo análogo pode ser dito acerca das grandes correntes teóricas da psicologia, com a diferença de que, nelas, deseja-se representar o sujeito psicológico ou o sujeito do comportamento, isso a partir de expedientes próprios à pesquisa científica. No caso da filosofia, durante muito tempo o espanto diante da inextricável intimidade entre o homem e as coisas, entre o sujeito e outrem, acabou cedendo em favor de um desses polos. Para fazer cessar a tensão entre eles, os paradoxos da nossa condição corporal e da comunicação com os outros e com o mundo receberam ora o véu da explicação idealista, ora o véu da explicação materialista, ora explicações vitalistas, ora mecanicistas. Ou foram absorvidos em modelos dualistas de organização do universo: a oposição entre matéria e forma, entre existência e essência, entre aparência e realidade. Foi na sombra desse movimento pendular que a psicologia emergiu, no século XIX, como ciência independente.
Para os primeiros psicólogos dessa era, tais como Wundt e James, promover a Psicologia como ciência implicava distanciar-se da filosofia e, com isso, adotar um ponto de vista empírico, não exclusivamente reflexivo, sobre as questões a ser tratadas. E promovê-la como ciência independente significava tentar delimitar um campo de estudos singular em relação ao da física, da biologia e da fisiologia. Esse setor específico ao qual se dedicar seria a subjetividade, tal como "descoberta" pela filosofia, mas abordada segundo as regras que regiam aquelas ciências naturais.

Merleau-Ponty (2003a) denomina pequeno racionalismo a ideologia que dominava as formas de saber vigentes no século XIX e que se resume à busca pela "explicação do Ser pela ciência" (Merleau-Ponty, 2003a, p. 238). Por um momento, difícil de se reviver, posto que não coincide com o pensamento de hoje, esperou-se que a razão fosse capaz de enclausurar a totalidade do real numa rede de relações causais. Esse racionalismo fiava-se, primeiro, no mito das leis da natureza, na ideia de uma ciência já feita nas coisas e à qual caberia à ciência dos homens se igualar. Confiava, ainda, no mito da explicação científica. Merleau-Ponty (2003a, p. 239) comenta:

A razão confundia-se com o conhecimento das condições ou das causas: por toda parte em que um condicionamento fosse desvelado, pensava-se ter feito calar toda questão, resolvido o problema da essência com aquele da origem, reconduzido o fato sob a obediência da causa.

Sob esse regime, cada regularidade conquistada pelo determinismo significava a desarticulação do "sentido metafísico". Com efeito, a única possibilidade de encontro da ciência com a metafísica abrigava-se na questão de saber "se o mundo é um único grande Processo submetido a um único 'axioma gerador'” (Merleau-Ponty, 2003a, p. 239).

Esse racionalismo é o produto, a herança desfigurada de um "grande racionalismo", o do século XVII, que se deteriorou nos dois séculos ulteriores, considera Merleau-Ponty (2003a). 0 fundamento comum

\footnotetext{
1 De modo a não dar ensejo a equívocos, cumpre salientar que o termo estruturalismo, na psicologia, possui duas acepções antagônicas. Os psicólogos norte-americanos introduziram os termos estrutura e estruturalismo para se remeter a teorias do fim do século XIX que buscavam explicar os fatos mentais a partir da combinação de elementos simples, tais como as sensações (Lagache, 1971). Por outro lado, o estruturalismo também faz referência a traços teóricos que remontam, por exemplo, aos princípios da teoria da forma, que rejeita a ideia de elementos simples da consciência. É nessa acepção que utilizamos o termo em questão.
} 
sobre o qual se encontravam o conhecimento da natureza e a metafísica é o privilégio perdido desse século XVII. Malgrado o fato de que a criação da ciência da natureza tenha ocorrido ali, não se fez do objeto da ciência a fórmula da ontologia. Ele figurava antes como um aspecto do ser por meio do qual se aprendia a reconhecer as possibilidades da razão. Além do plano do ser exterior, para filósofos como Descartes, Spinoza e Leibniz havia os problemas do ser do sujeito, da alma, das ideias. Mais expressivas ainda eram as questões que se colocavam a propósito da ação recíproca entre o interior e o exterior, a ação do espírito sobre o corpo e a do corpo sobre o espírito, problemas que a ontologia cientificista cria suprimir "instalando-se sem crítica no ser exterior como meio universal" (Merleau-Ponty, 2003a, p. 241).

Seja como for, por meio da comunicação entre a efetiva existência das coisas extensas, parciais e descontínuas, e a extensão pensada por nós, contínua e infinita, um equilíbrio fora encontrado, no século XVII, entre a ciência e a filosofia. Enquanto a convicção de que um entendimento infinito poderia ser encontrado na evidência interior não se revelou como a ameaça de uma nova escolástica, aquele equilíbrio pôde durar (Merleau-Ponty, 2003a).

Se um dos caminhos que se anunciavam nessa história da filosofia moderna era o da ciência da natureza, é preciso considerar também o desenrolar do que Merleau-Ponty (2003a) denomina "descoberta da subjetividade". É evidente que, ao falar em descoberta, o autor não entende tratar de uma subjetividade que estivesse à espera dos filósofos para ser revelada, mas do fato de que cada pensamento acerca da subjetividade não poderia se deixar ignorar pela filosofia vindoura. De Montaigne e Pascal a Descartes e Locke, de Rousseau a Maine de Biran, de Kant a Kierkegaard, o desacordo das filosofias em torno da subjetividade não recai sobre sua consideração como coisa ou substância. É antes a dialética do particular e do universal que se esconde sob as divergências. Merleau-Ponty (2003a, p. 250) escreve: "No fundo, há apenas duas ideias sobre a subjetividade: aquela da subjetividade vazia, solta, universal, e aquela da subjetividade plena, cravada no mundo". A reflexão, nas oscilações deste novo pêndulo, desvelou o irrefletido e a historicidade do saber.
Cumpre dizer que o próprio desenvolvimento do racionalismo cientificista auxiliava, ainda que por meio de aportes negativos, a avivar o problema da subjetividade. No interior das ciências, tendia-se a uma separação cada vez mais rigorosa entre a realidade do mundo tal como apresentada por elas e o aspecto qualitativo, perceptivo e, portanto, subjetivo do mundo tal como se mostra a nós enquanto seres providos de uma organização psicofísica (Gurwitsch, 2002). Heidegger (1994) resume essa situação advinda com a Modernidade dizendo que, quanto mais o mundo disponibilizava-se como mundo conquistado e fixado em representações científicas, mais peremptoriamente se elevava o sujeito, exigindo, por conseguinte, uma teoria do homem. Representar o mundo natural implica trazê-lo diante de si, relacioná-lo a um sujeito da representação, que se revela ao mesmo tempo como região do ser em que falha toda medida. 0 objetivismo solicita, pois, o subjetivismo num jogo de reciprocidade. 0 mundo como imagem constituída coincide com o advento do homem como "subjectum no meio do ser" (Heidegger, 1994, p. 121).

Na confluência do racionalismo cientificista e da "descoberta" da subjetividade, o projeto de uma psicologia científica, que emerge no século XIX, caracteriza-a justamente como ciência da subjetividade (Canguilhem, 2002).

\section{A psicologia científica}

Wundt (2005), em Princípios de psicologia fisiológica², afirma combinar duas "ciências" que, embora tratem de um mesmo tema, seguiram trajetórias distintas na história do pensamento: a fisiologia e a psicologia. Cabe esclarecer que essa psicologia a que se refere Wundt é a psicologia racional, ou psicologia filosófica. Em outras palavras, a própria filosofia, sempre que se dedicava a investigações especulativas acerca das "faculdades da alma". O projeto de Wundt é dedicar-se ao "domínio limítrofe" entre os fenômenos biológicos que sustentam nossos sentidos externos e a experiência interna tal como revelada pelos métodos de observação de si mesmo. Seu objetivo é investigar "os pontos de contato da vida interna e externa" (Wundt, 2005, p. 1), o que exige a comparação dos dados tradicionalmente

\footnotetext{
2 Boring (1950, p. 322) trata esta obra como "o mais importante livro na história da psicologia moderna".
} 
fornecidos separadamente pela fisiologia e pela psicologia filosófica. Segundo o autor, essas duas disciplinas, apartadas, esquivavam-se facilmente dos problemas inerentes à "conexão mútua da existência interna e externa" (Wundt, 2005, p. 2). A nova ciência por ele proposta, a psicologia fisiológica, ou psicologia experimental, dedicar-se-ia justamente a essa convergência olvidada.

Para tanto, segundo Wundt seria necessário realizar importantes opções metodológicas. No que tange à relação entre o interno e o externo, a psicologia fisiológica deveria percorrer os caminhos que conduzem de fora para dentro. "Ela começa pelos fenômenos fisiológicos e tenta demonstrar o seu modo de influência sobre o domínio da observação interna; em seguida, seu exame se estende às reações que o ser interno exerce contra o ser externo", afirma Wundt (2005, p. 2). Trata-se de não se instalar imediatamente "no meio do teatro da observação interna" (Wundt, 2005 , p. 2). A psicologia fisiológica penetra nele a partir do exterior. Apenas desse modo seria possível consagrar-se ao sujeito sustentando-se no método experimental, que consiste na modificação das condições do fato estudado com vistas à obtenção de alterações quantitativamente determináveis. Wundt (2005, p. 5) comenta: "existe apenas experimentações psicofísicas", e não psicológicas. Aquelas devem servir para esclarecer a natureza dos fatos internos.

Isso implica afirmar que, diferentemente do físico, que se aplica à mensuração das forças da natureza por meio da determinação matemática de seus efeitos, a mensuração em psicologia pode apenas esperar estudar os efeitos internos pelo conhecimento matemático de suas causas.

Nessa mesma direção, em um trabalho posterior, Wundt (1973) aplica-se a desenvolver o que chama de "princípio das resultantes criativas". Trata-se de atestar que, em relação aos elementos das combinações psíquicas, os processos psicológicos representariam novas criações, irredutíveis à soma daqueles elementos. É o que ocorreria, por exemplo, no caso das imagens espaciais. A qualidade resultante das sensações retinianas de luz e das sensações devidas aos movimentos e ajustamentos dos olhos é algo novo, que não se encontra contido naqueles elementos, afirma Wundt. Tem-se, pois, que, em relação à lei de constância da matéria, válida no que tange às forças da natureza, nossa vida mental revela uma "combinação de crescimento criativo e regularidade estrita" (Wundt, 1973, p. 166). Isso quer dizer, comenta o autor, que as resultantes do fenômeno psíquico não podem ser determinadas de antemão, e que o psicólogo assemelha-se a um "profeta com os olhos voltados para o passado" (Wundt, 1973, p. 167).

Para Abib (2009), se a psicologia fisiológica de Wundt aproxima-o das ciências da natureza, o princípio das resultantes criativas aproxima-o das ciências da cultura. Isso porque esse princípio estabelece uma incompatibilidade entre a causalidade psíquica e a causalidade física. Diante de nossos propósitos neste ensaio, cumpre chamar a atenção para o fato de que o princípio das resultantes criativas pode ser considerado como uma tentativa de abordar problemas de estrutura ${ }^{3}$.

Essa resistência ao reducionismo naturalista no interior da obra de Wundt remete-nos aos dualismos seculares aos quais fizemos referência no início deste ensaio e que nos auxiliam a situar historicamente a psicologia no interstício de formas diversas de saber, ou seja, numa perspectiva essencialmente plural. A comparação que Abib (2009) opera entre o projeto científico da psicologia em Wundt e em Willian James encaminha-nos a uma conclusão semelhante.

Para James (2009), o objeto da psicologia é o estudo de nossa vida mental enquanto fenômeno intrínseco à história natural. 0 autor afirma: "uma mente é um objeto num mundo de outros objetos, sua relação com estes outros objetos deve ser examinada de perto" (James, 1950, p. 199). Isso significa dizer que o psicólogo deveria, em grande medida, dedicar-se ao estudo das condições da vida mental, ou seja, suas relações com a atividade cerebral, com outras partes do corpo e com o ambiente físico, tanto no que diz respeito à sua mera reatividade a esse ambiente, quanto à sua capacidade de modificá-lo por meio de performances inteligentes. Para tanto, é preciso, primeiramente, que o psicólogo prive-se de questões de cunho metafísico tais como a da possibilidade de existência de algo como um estado mental. James (2009, p. 318) comenta:

\footnotetext{
3 Sem denotar a intenção de incluir a obra de Wundt no campo do associacionismo estrito, lembramos a seguinte afirmação de Lagache (1971, p. 81): “Até aproximadamente 1920 o termo 'estrutura' foi pouco usado; isto não significa que a preocupação pela estrutura não existisse: o associacionismo, por exemplo, pode ser considerado como uma tentativa para resolver problemas de estrutura".
} 
"Toda ciência particular, no intuito de encontrar de todo seus próprios particulares, deve fazer um certo número de suposições convenientes e declinar de ser responsável por questões acerca das quais a mente humana continuará a indagar-se". A física, por exemplo, assume a existência do mundo material, mas abstém-se de mostrar como a experiência desse mundo é possível. Além disso, afirma James, a particularização das ciências naturais se dá em benefício da efetividade prática. Escreve o autor:

Todas as ciências naturais visam predição e controle práticos e, em nenhuma outra, isso é mais o caso do que na psicologia atual. Vivemos cercados por um enorme número de pessoas definitivamente interessadas no controle dos estados mentais e incessantemente ansiosas por um tipo de ciência psicológica que as ensine a agir. 0 que todo educador, todo diretor de presídio, todo médico, todo sacerdote e todo superintendente de asilo pedem à psicologia são regras práticas. Tais pessoas pouco ou nada se importam com o terreno filosófico fundamental do fenômeno mental, mas importam-se imensamente com o aperfeiçoamento das idéias, disposições e condutas dos indivíduos particulares que se encontram sob seus encargos (James, 2009, p. 319, grifo do autor).

Abib (2009) destaca a diferença entre as concepções de ciência psicológica para Wundt e James. Embora concordem com a necessidade de que essa ciência afaste-se definitivamente da psicologia filosófica, para o primeiro a psicologia deve constituir-se como ciência empírica intermediária, na medida em que pode apenas contar com deduções retrogressivas. Para o segundo, a psicologia reúne os elementos suficientes para se erigir como ciência natural voltada para a dedução preditiva e para a eficácia prática. Abib (2009, p. 199) sintetiza a questão ao afirmar que, "como projeto científico, já no seu ponto de partida, a psicologia é plural”.

Pode-se dizer que, desde o início, o sujeito psicológico, enquanto setor de investigação da psicologia, mostra pouca disponibilidade para se deixar representar como coisa entre outras coisas. Dito de outra maneira, o sujeito psicológico resiste a ser reduzido a um único setor de objetividade: a natureza, concebida como soma de fenômenos partes extra partes. Uma fissura instala-se desde o início deste projeto. Em sua evolução subsequente, a psicologia, contudo, firma-se como psicologia científica, ou seja, apartada da filosofia, mas não como ciência unitária. 0 que se observou, com efeito, "foi uma notável proliferação de psicologias científicas" (Abib, 2009, p. 199).

\section{A psicologia no século XX e a ideia de estrutura}

Piaget (1972) ocupou-se da descrição das tendências da psicologia no século XX. Cumpre salientar que tal empresa foi realizada a partir de uma perspectiva abertamente cientificista. Para o autor, deve se estabelecer uma clara fronteira entre as psicologias científicas e as psicologias filosóficas, tributárias da introspecção. Caberia às psicologias científicas, no estudo da subjetividade, da consciência ou do comportamento, guiar-se por uma perspectiva descentrada em relação ao eu do observador e pelo expediente normal de pesquisa: a busca de fatos experimentais passíveis de articulação em leis explicativas.

Para Piaget (1972), a diversidade daquelas tendências repousa sobre os vários modelos utilizados para se representar a vida mental. Em todas elas, observa-se o ímpeto de se ultrapassar as descrições em direção da interpretação. Todas realizam a descrição de fatos gerais e de relações constantes passíveis de estabelecer leis. Também operam com sistemas mais ou menos formais de dedução ou coordenação das leis. Esses dois passos devem, contudo, efetivar-se num esforço explicativo. 0 autor comenta: "Para alcançar a explicação é indispensável concretizar a dedução de leis sob a forma de 'modelos' que, se supõe, representem os processos reais e, ao mesmo tempo, exprima-os sob a forma de operações dedutivas" (Piaget, 1972, p. 151). Conforme Piaget, a pluralidade da psicologia revela-se justamente na multiplicidade de hipóteses explicativas. Afinal, considera o autor, a vida mental sustenta-se na vida orgânica, desenvolve-se na vida social e manifesta-se por meio de estruturas lógicas, psicolinguísticas, dentre outras. Segundo ele, a diversidade de modelos adviria das tentativas reducionistas de caráter organicista, fisicalista ou sociológico, bem como das tentativas de exprimir a vida psicológica a partir da dialética entre o instinto e o eu, das manifestações do comportamento, ou do desenvolvimento de maneira geral.

Em todos esses modelos, Piaget (1972) observa o progresso das tendências estruturalistas. Segundo o autor, o ponto de vista estruturalista impõe-se devido à sua profundidade. Trata-se de, aquém dos aspectos biológicos, físicos e sociais, buscar as

Psicol. Argum. 2013 jul./set., 31 (74), 537-546 
estruturas do comportamento, do pensamento, da afetividade, que resultam da "interiorização progressiva das ações" (Piaget, 1972, pp. 139-140). A partir dele, obtém-se a possibilidade de abordar a vida mental numa perspectiva mais ampla do que a noção de consciência pode oferecer, englobando esta última e conservando suas ligações com o organismo e a vida coletiva. As análises de Piaget acerca do estruturalismo expresso nas tendências fisicalista, psicossosiológica e nos estudos de psicogenética revelam a concepção de estrutura que defende.

No que diz respeito ao fisicalismo, Piaget (1972) lembra que a percepção logo se mostrou um fenômeno privilegiado para os estudos em psicologia experimental, pois parecia diretamente ligada ao mundo físico. Com efeito, os pioneiros da psicofísica, tais como Weber e Fechner, buscavam justamente atrelar os processos perceptivos a processos físicos. Suas tentativas revelam um caráter associacionista de natureza atomística. Estudavam as relações constantes entre as quantidades físicas e suas expressões subjetivas, as sensações, que eram consideradas isoladamente. Tomavam as sensações como os elementos da consciência e que, por associação, ligavam-se uns aos outros.

Os estudos acerca da percepção realizados pela psicologia da Gestalt denotam, por outro lado, um fisicalismo estruturalista. Piaget (1972) refere-se à psicologia da Gestalt como uma das fontes do estruturalismo, tal como ficou conhecido em meados do século XX. Segundo o autor, foram significativas as influências indiretas daquela escola, que se estenderam durante muito tempo. Nela, a percepção é tratada como um fenômeno total. Afirma-se que uma melodia, uma fisionomia, uma figura geométrica não são o resultado de processos de associação mental, mas fenômenos percebidos diretamente. Os representantes da psicologia da Gestalt dedicaram-se ao estudo das leis dessas totalidades, como a lei da segregação entre figura e fundo, e a lei da boa forma, que prescreve simplicidade, regularidade e simetria às figuras que se destacam na percepção. Para Piaget (1972, p. 164), a explicação que a psicologia da Gestalt propõe em relação às formas percebidas é "bela e simples". Trata-se de invocar o que se denominou isomorfismo. As formas perceptivas seriam expressões de estruturações nervosas imediatas, elas mesmas organizadas segundo as leis dos campos físicos, que se configuram como totalidades não aditivas, em que o todo não equivale à soma das partes.

A crítica que Piaget (1972) endereça à psicologia da Gestalt versa sobre a possibilidade de se compreender fenômenos tais como a nossa capacidade lógica a partir de um estruturalismo fisicalista. Para o autor, é a partir da consideração de estruturas biológicas e psicológicas que se poderia avançar na reflexão sobre o próprio conhecimento físico. Essa conclusão é semelhante à de Gurwitsch (2002), que aponta a necessidade que a teoria da forma possui de ser complementada. $\mathrm{O}$ organicismo estrutural de Kurt Goldstein, que, a partir de estudos sobre a afasia, destacou a função simbólica enquanto estrutura de comportamento, é tratado pelo autor como exemplo de complemento ao fenomenalismo da teoria da forma.

No que tange às tendências psicossociológicas, Piaget (1972) relembra as disputas clássicas que giram em torno da afirmação do primado da sociedade sobre o indivíduo, como leva a crer o fenômeno da aquisição da linguagem, ou em torno do primado das tendências naturais do indivíduo na formação social, como certos extratos psicanalíticos dão a entender. Para o autor, opor uma lógica social a uma lógica individual é um exercício vão. Segundo ele, toda ação humana revela uma mesma estrutura geral, "sem hierarquia entre seus aspectos coletivos e seus aspectos individualizados" (Piaget, 1972, p. 177). É o que revela a estreita relação entre os achados do estruturalismo linguístico e os estudos acerca do desenvolvimento das operações lógicas na criança. Piaget (1972, p. 181) comenta: "as estruturas gerais mentais e as estruturas gerais sociais possuem formas idênticas e testemunham, pois, um parentesco de natureza, cujas raízes sem dúvida são em parte biológicas". A leitura que faz da antropologia estrutural de Lévi-Strauss caminha nessa direção $0^{4}$. Piaget destaca o fato de que, para caracterizar as estruturas do parentesco, Lévi-Strauss recorre às estruturas da álgebra geral, às noções de grupos, redes etc. Ora, trata-se de fazer coincidir a explicação sociológica com a construção de estruturas lógicas, que, por sua vez, possuem uma gênese de natureza estrutural ao longo do desenvolvimento infantil.

Segundo Piaget (1972), a psicologia infantil ocupa um papel central na psicologia devido à possibilidade

\footnotetext{
4 Para a leitura de considerações mais específicas acerca do estruturalismo de Lévi-Strauss, conferir Piaget, 1974.
} 
de compreender a natureza e o funcionamento das condutas a partir do estudo da sua formação nas crianças. Diferentemente dos pressupostos inatistas e dos empiristas, que culminam na ideia de desenvolvimento como acumulação aditiva de elementos isolados, a psicologia da criança ensina que o desenvolvimento consiste na construção real de estruturas. O que significa a subversão, ao mesmo tempo, do primado dos fatores orgânicos e do primado da ação do mundo adulto na ontogênese.

0 estudo da psicogênese na criança permite analisar a construção das estruturas da inteligência. No rastro de uma psicologia animal que concebe a estreita interação entre maturação e experiência a partir da constatação da mobilidade adaptativa dos animais, Piaget destaca, por exemplo, a inteligência sensório-motora, que se constitui anteriormente à linguagem e, portanto, independentemente dela. De acordo com o autor, as operações intelectuais nascem da ação e se constituem como ações interiorizadas. Em seu desenrolar funcional, as ações são coordenadas por um fator de equilibração, a exemplo dos processos de autoregulação no sentido biológico, o que liga a inteligência às homeostases próprias à vida orgânica. Piaget (1972, p. 209) afirma: "a equilibração assim concebida repousa sobre as compensações ativas do sujeito às modificações exteriores".

A equilibração remete-nos ao problema da gênese da própria estrutura. Segundo Piaget (1974), as estruturas autênticas possuem uma natureza operatória. Ou seja, não se deixam conceber nem como estrutura pré-formada biologicamente nem como estrutura contingente, pré-formada no mundo exterior.

Daí as seguintes questões: qual o estatuto da ideia de estrutura? Trata-se de um simples construto teórico, passível de articular os achados empíricos em diversas áreas do conhecimento, inclusive nos diversos setores em que o pensamento psicológico se instala? Ou ela exige uma reforma da teoria do conhecimento capaz de subverter o realismo da psicologia como ciência natural (Merleau-Ponty, 2006)? É possível uma psicologia estrutural desvinculada de uma filosofia da estrutura?

\section{0 estatuto filosófico da noção de estrutura}

Lagache (1971) também identifica o estruturalismo como um dos traços dominantes da psicologia de meados do século XX. Numa direção semelhante à de Piaget, afirma que o combate ao atomismo psicológico devido a filósofos como Bergson, na França, e Dilthey, na Alemanha, foi eclipsado pelo êxito da psicologia da Gestalt. De acordo com Lagache, a psicologia da Gestalt pautava-se pela rejeição à dedução do conjunto a partir do conhecimento das partes, bem como na recusa à ideia de que o estudo das partes pode ser completo sem referência ao conjunto. 0 desenvolvimento dessa perspectiva estruturalista colaborou para que se desarticulassem as principais antinomias da psicologia do século XIX: a do organismo e do ambiente, do amadurecimento e da aprendizagem, do indivíduo e da sociedade, do comportamento e da consciência, do psíquico e do somático, do passado e do futuro. Todos esses são conceitos que deixaram de ser utilizados a partir de um sistema de oposição que os isolava permanentemente. Com efeito, a rejeição da causalidade unilinear em prol da causalidade em rede freou o avanço das teorias unilaterais, que Piaget denomina reducionistas: o biologismo, o psicologismo, o sociologismo.

Tratamos, pois, de uma evolução da psicologia. Para Merleau-Ponty (2001), essa evolução, na medida em que se reveste como superação daquelas antinomias filosóficas e metodológicas, implica sobretudo a revisão da oposição radical entre a filosofia e a psicologia operada no século XIX. A importância da noção de estrutura nesse processo deve-se justamente ao fato de que, como bem observa Nunes (2010, p. 264), ela “...obedece a um nítido registro epistemológico”, que subverte as relações clássicas entre o subjetivo e o objetivo.

Merleau-Ponty (2006) trata desse registro epistemológico da noção de estrutura. 0 ponto de partida do filósofo remonta ao problema clássico das relações entre a alma e o corpo. A noção de estrutura, tal como revelada pela psicologia da Gestalt serve-lhe de apoio para a crítica ao estudo do comportamento do ponto de vista naturalista, como no caso das pesquisas baseadas na ideia de reflexo. Contrariamente à suposição de que os processos de aprendizagem ocorrem segundo uma espécie de soldagem entre movimentos e estímulos individuais, o filósofo constata que a aquisição de um hábito ou de uma habilidade qualquer é sistemática, e revela o desenvolvimento do poder de responder a uma certa forma de situações por meio de um certo tipo de soluções. Ao longo desse exercício crítico, Merleau-Ponty recusa a explicação isomórfica privilegiada pela escola da Gestalt. 0 filósofo concebe a

Psicol. Argum. 2013 jul./set., 31 (74), 537-546 
ideia de estrutura como "a junção de uma ideia e de uma existência indiscerníveis, o arranjo contingente pelo qual os materiais passam a ter um sentido diante de nós, a inteligibilidade em estado nascente" (Merleau-Ponty, 2006, p. 223). Ou seja, interessa ao filósofo aquilo que Nunes (2010, p. 268) chama de "relação simétrica e inversa entre gênese e estrutura". A forma que se expõe, por exemplo, na estrutura figura-fundo possui um sentido que serve de apoio à análise intelectual. 0 próprio ato simbólico denota um fenômeno de estruturação. Ao mesmo tempo, a forma não é uma ideia. Ela efetivamente se altera e se reorganiza diante de nós.

Por esse motivo, Merleau-Ponty (2006, p. 226) toma a estrutura do corpo próprio, o corpo vivido em primeira pessoa, como a "realidade fundamental". 0 corpo não se deixa reduzir à análise anatômica. Não há nenhuma parte do território cerebral que não se mostre profundamente atrelada ao funcionamento global do sistema nervoso. Assim como não há atividade funcional que não seja profundamente alterada pela retirada de um desses territórios. 0 mesmo vale no tocante à relação do comportamento superior, simbólico, com as dialéticas que lhe são subordinadas, a dialética vital, do organismo e do meio, e a dialética física, que se estabelece entre o sistema físico e suas condições topográficas. Quando tudo funciona corretamente, elas dificilmente são reconhecíveis no conjunto do comportamento humano. Sua condição iminente é, todavia, comprovada nos casos de desintegração do comportamento devido a lesões cerebrais. Em outras palavras, não é possível discernir as condições da existência no todo que elas colaboram para estruturar e que culmina em atos de significação. Por outro lado, comenta Merleau-Ponty (2006, p. 224, grifo do autor), "a essência do todo não pode ser pensada concretamente sem elas e sem sua história constitutiva". No contexto da reflexão do filósofo, isso significa afirmar o caráter transcendental do comportamento, que não pode ser considerado como coisa que existe em si, mas como "um conjunto significativo para uma consciência que o considera" (Merleau-Ponty, 2006, p. 225). Ao mesmo tempo, essa consciência mostra-se inerente à vida orgânica, e esta deve ser considerada não enquanto reunião de partes materiais, mas enquanto história viva das etapas dialéticas que a consciência atravessou, o que a distingue de suas concepções criticistas. 0 corpo possui, pois, uma idealidade, mas essa ideia emerge do acaso da existência. Daí a seguinte consideração por parte de Merleau-Ponty (2006, p. 227, grifo do autor):
A noção de Gestalt nos levava, por um desenvolvimento natural, ao seu sentido hegeliano, quer dizer, ao conceito antes que tenha se tornado consciência de si. A natureza, dizíamos, é o exterior de um conceito. Mas, justamente, o conceito como conceito não possui exterior, e restava à Gestalt ser pensada como unidade do interior e do exterior, da natureza e da ideia. Correlativamente, a consciência para a qual a Gestalt existe não era a consciência intelectual, mas a experiência perceptiva.

0 que as palavras de Merleau-Ponty ressaltam é, justamente, o fato de que a investigação acerca das estruturas conduz ao reconhecimento de que o objeto das ciências é impensável sem que se assumam as unidades de significado que uma consciência vê nele se desenvolver. E que, por outro lado, essa constatação exige uma reconstrução da noção de consciência. 0 desvelamento de um campo transcendental a partir do ponto de vista estruturalista permite que o psicologismo seja superado. Isso quer dizer que o sentido e a estrutura do percebido não podem ser reduzidos a eventos psicofisiológicos, o que faria da razão um mero acaso, e que a Gestalt pode ser reconhecida como um fenômeno originário. Precisamos levar em conta, contudo, que a "forma" não é a condição de aparição do mundo, o que lhe daria um sentido kantiano, mas é a própria aparição do mundo. Nas palavras de Merleau-Ponty (1945, p. 74), o fenômeno de estrutura "é o nascimento de uma norma e não se realiza segundo uma norma, é a identidade entre o exterior e o interior e não a projeção do interior no exterior". Em outros termos, a forma não se revela uma espécie de razão pré-existente.

Com efeito, a ideia de estrutura exige que as ciências que dela se ocupam, bem como a filosofia, recoloquem a consciência diante de sua vida pré-reflexiva e que a despertem para sua própria história (Merleau-Ponty, 1945).

É o que se constata igualmente nas análises de Nunes (2010). Segundo o autor, o estruturalismo propõe "verdadeiras questões-limite" (Nunes, 2010, p. 262), que se inserem, já mencionamos isso, num registro nitidamente epistemológico. Nunes considera que a reconstituição da possibilidade do pensamento formal inerente ao desenvolvimento intelectual operada por Piaget a partir do ponto de vista estrutural-genético evidencia-se como uma exigência epistemológica. De outra forma, não se vê como, fundando-se em fatos mentais isolados, chegar-se-ia à gênese das 
formas mentais. 0 estruturalismo circunscreve domínios em que se possa tratar de "sistemas de transformações autorreguláveis” (Nunes, 2010, p. 263). Esse é o caso das estruturas mentais abordadas por Piaget. O problema das estruturas, todavia, não se esgota aí. Onde elas têm sua origem, afinal?

Nunes (2010) busca resolver este problema a partir das estruturas com que trabalha a antropologia de Lévi-Strauss. De acordo com Nunes, essa antropologia tem o privilégio de concentrar a problemática de todos os estruturalismos. Ela revela como não se pode prescindir de complementar qualquer atividade de pesquisa de cunho estrutural por questões relativas à atividade operatória do sujeito.

O etnólogo, enquanto aplica o seu pensamento para compreender os fenômenos culturais, encontra-se nesse campo, onde convergem a sua atividade construtiva, que não é jamais atividade do Eu individual, e a atividade, também construtiva, de outros sujeitos, da qual irrompem, por efeito das mesmas operações, as estruturas inconscientes que o modelo elaborado pelo primeiro converterá em objeto de conhecimento (Nunes, 2010, p. 267).

Escrevendo desse modo, Nunes (2010) explicita a convergência entre o princípio que norteia a experiência racional do cientista e aquele que fundamenta a própria atividade do sujeito pesquisado. Na verve de Lévi-Strauss, esse princípio é o inconsciente enquanto termo estruturante e genético. No caso da antropologia em apreço, isso quer dizer que a experiência simbólica atualiza-se duplamente, primeiro enquanto estrutura vivida, depois como modelo teórico-estrutural.

\section{Considerações finais}

A psicologia é plural não apenas em função da variedade de modelos explicativos voltados à vida mental e ao comportamento, mas por causa de um fator mais essencial: sua constituição enquanto prática cultural inserida no movimento de tradições de pensamento psicológico no interior da própria história da cultura (Abib, 2009).

0 privilégio que demos à discussão da presença do pensamento estruturalista na psicologia conduz-nos, justamente, para a consideração da história do conhecimento psicológico enquanto tipo de investigação pertencente à história da cultura.
Em consonância com Foucault (2005), poder-se-ia afirmar que o estruturalismo é fruto do domínio epistêmico moderno, cujo volume deve-se às íntimas relações entre a reflexão filosófica, as ciências empíricas - que, para Foucault, são as ciências da vida, da produção e da linguagem - e as disciplinas matemáticas. É no interstício desses saberes que emergem as ciências humanas; é nele que pode surgir algo como a ideia de estrutura. As ciências humanas não se constituem como análise da natureza do homem. Antes, instalam-se entre a positividade do homem como ser vivo que trabalha e fala, e aquilo que permite a esse ente interessar-se em conhecer a essência da vida, as leis que regem as relações de trabalho e a lógica da expressão linguística.

Quanto à estrutura, ela não figura nas ciências como o fundamento final da experiência. Ela é, antes de tudo, um instrumento de conhecimento (Bimbenet, 2004; Merleau-Ponty, 2003b). Seu valor, não obstante, advém de ela admitir que o homem possui duas faces: ele é significante e, ao mesmo tempo, suas intenções tendem a se generalizar em processos e a se fazer mediar pelas coisas, pela vida social (Merleau-Ponty, 2003b). O homem, dessa forma, cerca-se de sentido e pode dar-se a conhecer esse sentido. Em outros termos, o ser mergulhado na estrutura mostra-se capaz de conhecer a estrutura (Bimbenet, 2004).

$\mathrm{Na}$ medida em que lida com estruturas, inclusive para encontrar nelas a aurora do conhecimento, como faz a epistemologia genética de Piaget, a psicologia apresenta sua face filosofante, que coloca em questão o próprio conhecimento. A filosofia, por outro lado, na medida em que se interessa por radicalizar o conceito de Gestalt, aproxima-se dos fatos trazidos pelas ciências e, por conseguinte, molda-se como filosofia concreta.

Tratamos, pois, de um panorama de reaproximação entre as ciências humanas e as humanidades que, longe de aventar o abandono da reflexão rigorosa, contesta as fronteiras daquelas formas de saber (Ribeiro, 2001).

\section{Referências}

Abib, J. (2009). Epistemologia pluralizada e história da psicologia. Scientiae Studia, 7(2), 195-208.

Bimbenet, E. (2004). Nature et humanité: Le problème anthropologique dans l'ouvre de Merleau-Ponty. Paris: Vrin.

Psicol. Argum. 2013 jul./set., 31 (74), 537-546 
Boring, E. (1950). A history of experimental psychology. (2nd ed.). New York: Appleton-Century-Crofts.

Canguilhem, G. (2002). Qu'est-ce que la psychologie? In G. Canguilhem. Études d'histoire et de philosophie des sciences: Concernant les vivants et la vie. (7. ed., pp. 365381). Paris: Vrin (Originalmente publicado em 1958).

Foucault, M. (2005). Les mots et les choses. Paris: Gallimard (Originalmente publicado em 1966).

Gurwitsch, A. (2002). Quelques aspects et quelques développements de la psychologie de la forme. In A. Gurwitsch. Esquisse de la phénoménologie constitutive (pp.257-312). Paris: Vrin (Originalmente publicado em 1936).

Heidegger, M. (1994). L'époque des "conceptions du monde". In M. Heidegger. Chemins qui ne mènent nulle part (pp.99-146). Paris: Gallimard (Originalmente publicado em 1949).

James, W. (1950). The principles of psychology. [S.l.]: Dover. (Originalmente publicado em 1890).

James, W. (2009). Apelo para que a psicologia seja uma “ciência natural”. Scientiae Studia, 7(2), 317-324 (Originalmente publicado em 1892).

Lagache, D. (1971). Estrutura em psicologia. In R. Bastide (Org.). Usos e sentidos do termo "estrutura" (pp. 8182). São Paulo: Herder/Edusp.

Merleau-Ponty, M. (1945). Phénoménologie de la perception. Paris: Gallimard.

Merleau-Ponty, M. (2000). Titres et travaux. Projet d'enseignement. In M. Merleau-Ponty. Parcours deux: 1951-1961 (pp . 9-35). Lagrasse: Verdier.
Merleau-Ponty, M. (2001). Les sciences de l'homme et la phénoménologie. In M. Merleau-Ponty. Psychologie et pédagogie de l'enfant: Cours de Sorbonne 1949-1952 (pp. 397-464). Lagrasse: Verdier.

Merleau-Ponty, M. (2003a). Partout et nulle part. In M. Merleau-Ponty. Signes (pp. 203-258). Paris: Gallimard (Originalmente publicado em 1960).

Merleau-Ponty, M. (2003b). De Mauss à Claude LéviStrauss. In M. Merleau-Ponty. Signes (pp.184-202). Paris: Gallimard (Originalmente publicado em 1960).

Merleau-Ponty, M. (2006). La structure du comportement. Paris: PUF. (Originalmente publicado em 1942).

Nunes, B. (2010). Gênese e estrutura. In B. Nunes. Ensaios filosóficos (pp.262-268). São Paulo: Martins Fontes.

Piaget, J. (1972). Épistémologie des sciences de l'homme. Paris: Gallimard.

Piaget, J. (1974). Le structuralisme. (6. ed.). Paris: PUF.

Ribeiro, R. (2001). Apresentação do organizador. In R. Ribeiro, O. Matos, T. Coelho, G. Schwartz \& C. Beisiegel (Org.). Humanidades: Um novo curso na USP (pp. 1129). São Paulo: Edusp.

Wundt, W. (1973). An introduction to psychology. (R. Pintner, Trad.). London: George Allen \& Company (Originalmente publicado em 1911).

Wundt, W. (2005). Principes de psychologie physiologique. (Vol. 1). (E. Rouvier, Trad.). Paris: L'Harmattan (Originalmente publicado em 1874). 